\title{
Amygdala stimulation disrupts the magnitude of reinforcement contribution to long-term memory
}

\author{
RAYMOND P. KESNER and RUSSELL G. ANDRUS \\ University of Utah, Salt Lake City, Utah
}

\begin{abstract}
Rats were trained in a symbolic delayed spatial matching-to-sample task using an eight-arm radial maze. Providing the animals with differential cues predicting a small or large reward on a subsequent retention test resulted in significantly better long-term retention $(23 \mathrm{~h})$ for the expectation of the large than the small reward. Electrical stimulation of the amygdala applied during, but not after, 10 sec exposure to the appropriate food cue predicting a large reward resulted in a retention deficit at the 23-h test delay. Similar treatments had no effect at a 20-min retention test. It is proposed that the amygdala is involved in processing of positive emotional attributes of specific memories.
\end{abstract}

In recent years there has been an ever-increasing interest in the role of the amygdala in mediating some aspect of mnemonic information processing. It has been suggested that the amygdala is involved directly either in storage or consolidation of information (Kesner \& Conner, 1974) or that the amygdala modulates consolidation in the form of arousal via nonspecific influences on the central nervous system (Gold, Hankins, Edwards, Chester, \& McGaugh, 1975). It has been assumed that the amygdala affects consolidation because of its presumed role in mediating reinforcement contingencies. Some support for this interpretation comes from the observation that amygdala-lesioned animals have difficulty identifying reinforcement stimuli (Weiskrantz, 1956), associating one of two objects with food reward (Jones \& Mishkin, 1972), and responding appropriately to change in the magnitude of reward (Schwartzbaum, 1960). Furthermore, there is an increase in the amplitude of electrical activity following rewarded barpresses, but not following nonrewarded responses (Norton, 1970). Also, increases in unit activity within the amygdala can be found when a click is paired with electric shock (Ben-Ari \& Le Gal La Salle, 1972). Unfortunately, the exact nature of the effect of reinforcement on memory has often not been specified. It has been proposed that reinforcement facilitates consolidation directly (Huston, Mueller, \& Mondadori, 1977 ) or indirectly via the activation of rehearsal processes (Kesner, 1977).

Support for this research was provided by Biomedical Research Support Grant NIH RR 07092-12. We thank Johanna Denbutter for her capable histological work. Requests for reprints should be sent to Raymond P. Kesner, Department of Psychology, University of Utah, Salt Lake City, Utah 84112.
The amygdala could also influence consolidation via its role in mediating emotional experiences (Baker, Kesner, \& Michal, 1981; Richardson, 1973). Support for the role of the amygdala in mediating emotional behavior comes from a variety of sources. Lesions of the amygdala in both animals and humans result in placidity, characterized by an almost complete lack of aggression, a marked reduced emotional reaction to noxious stimuli, and a reduction in acquiring new learning based on fear (Goddard, 1964; Narabayashi, 1972). Electrical stimulation of the amygdala in animals and humans can elicit a variety of emotional experiences (e.g., fear, rage, attack, flight, pleasure), with accompanying autonomic responses including changes in heart rate, blood pressure, respiration, piloerection, and pupillary dilation (Kaada, 1972; Mark \& Ervin, 1970). Rewarding self-stimulation can be obtained from the amygdala in both animals and humans (Heath, 1964; Wurtz \& Olds, 1963). Unpleasurable emotional experiences in humans are often accompanied by changes in the amygdala EEG (Heath \& Gallant, 1964).

On the basis of the above studies, which support a role for the amygdala in mediating emotional experiences, Kesner (1981) has proposed that the amygdala mediates the encoding, storage, and retrieval of both positive and negative emotional attributes of a specific memory, providing the reinforcement input is of sufficient intensity to elicit a relatively strong emotional reaction. The best support for this statement comes from studies that have manipulated the magnitude of reinforcement in situations involving either negative or positive reinforcement contingencies.

Gold et al. (1975) have shown that, in a passive avoidance learning situation, posttrial amygdala 
stimulation disrupted long-term retention when high footshock (FS) levels $(2 \mathrm{~mA}, 2 \mathrm{sec})$ were used, but had no disruptive effect on long-term retention as compared with unoperated controls and a facilitatory effect on long-term retention as compared with implanted controls when low FS levels $(.5 \mathrm{~mA}, .5 \mathrm{sec})$ were used.

In support of Gold et al.'s findings, other studies using high levels of FS also have found a disruption of long-term retention following amygdala stimulation (Baker, Kesner, \& Michal, 1981; Bresnahan \& Routtenberg, 1972; Kesner \& Conner, 1974; McDonough \& Kesner, 1971), while, in one study, in which relatively weak FS was used, amygdala stimulation failed to disrupt learning of conditioned emotional responses (Lidsky, Levine, Kreinick, \& Schwartzbaum, 1970). Even though no studies have investigated the effects of amygdala stimulation on magnitude of reinforcement within appetitive situations, it has been shown that monkeys and rats with amygdala lesions are less responsive to either increases or decreases in magnitude of reward (Kemble \& Beckman, 1970; Schwartzbaum, 1960).

It appeared to us to be of major importance to elaborate further on the possible role of the amygdala upon the magnitude of the reinforcement effect, using an appetitive task requiring mnemonic processing of information. Accordingly, in the present experiment, we decided to vary expected reward magnitude in a symbolic delayed matching-to-sample task and to test for possible disruptive effects of amygdala stimulation upon strong, as compared with weak, activation of presumably positive affective attributes.

\section{METHODS}

\section{Subjects}

Four male Long-Evans rats, with initial weights of 250-300 g, were used. The animals were food deprived to $80 \%$ ad-lib weight and allowed continuous access to water.

\section{Apparatus}

The animals were tested on an eight-arm maze fashioned after the one originally used by Olton (Olton \& Samuelson, 1976). The center platform was $34 \mathrm{~cm}$ in diameter. The eight arms radiating from the center platform at equidistant points were $10 \mathrm{~cm}$ wide and $86 \mathrm{~cm}$ long. The entire apparatus, constructed of whitepainted wood, was elevated approximately $50 \mathrm{~cm}$ above the floor. The testing room was well lighted by fluorescent lights and had numerous visual cues scattered around the room, including a sink, animal racks, support columns, pictures, and the brain-stimulation apparatus.

\section{Procedure}

The animals were initially trained using the standard eight-arm procedure with all arms reinforced. Reinforcement consisted of small pieces of Froot Loops cereal. Once the animals were familiar with the apparatus and were rapidly retrieving food from each of the reinforced arms, they were switched to a symbolic spatial matching-to-sample task. On each trial, a single arm was selected randomly for reinforcement (either a piece of Froot Loop or
Cocoa Puff cereal) and the animal was allowed to explore the maze until that arm was chosen. After returning to the center platform, the animal was momentarily restrained inside a translucent cover while the correct arm was rebaited. If the animal had received a piece of Froot Loop, then, following a delay, the animal would have to return to the same area (win-stay strategy) in order to receive one piece of Capt'n Crunch cereal. If the animal had received a piece of Cocoa Puff, then, following a delay, the animal would have to return to the same area in order to receive five pieces of Capt'n Crunch cereal. Half of the animals received the reverse order of significance for Froot Loop and Cocoa Puff reinforcement. When the restraining cover was removed, the animal was allowed to remain on the maze until the correct arm was traversed and the Capt'n Crunch reinforcement was consumed. The animal was then returned to the home cage and fed the daily maintenance ration of standard laboratory chow. The number of incorrect arms entered (errors) before entering the reinforced arm was used as index of retention.

Once the task was being performed with few errors, progressively longer retention intervals $(20 \mathrm{~min}, 2 \mathrm{~h}, 23 \mathrm{~h})$ were imposed on the animal. At this stage of training, and throughout the remainder of testing, the animals were allowed $10 \mathrm{sec}$ exposure on the baited arm and were then removed from the end of the arm and returned to a holding cage during the retention period (out of sight of the maze). An error was defined as an entry into an incorrect arm. Care was taken never to place the animal on the center platform from the same location or with the same orientation. Final performance for data collection used retention delays of $23 \mathrm{~h}$. Each animal received five trials for each reinforcement (Froot Loop or Cocoa Puff).

Following training, bilateral placement of bipolar electrodes (Plastic Products No. MS-303, .025 cm diam) aimed at the amygdala (coordinates: $2.0 \mathrm{~mm}$ posterior bregma, $3.0 \mathrm{~mm}$ lateral, $8.5 \mathrm{~mm}$ vertical, with head level) was performed under Nembutal anesthesia $(45 \mathrm{mg} / \mathrm{kg}$ ip). The electrode assembly was fixed to the skull with acrylic cement. The animals were allowed 10-14 days' recovery from surgery before retraining was begun.

All animals received 20 trials at a $23-\mathrm{h}$ retention test delay, with subseizure-level amygdala stimulation applied for $10 \mathrm{sec}$ during the consumption of either the Froot Loop or piece of Cocoa Puff reinforcement on half the trials and no brain stimulation on the other half of the trials. Thus, on a random basis, each animal received 5 trials in the presence or absence of brain stimulation during consumption of either Froot Loop or Cocoa Puff.

The animals were coupled to an Ortec two-channel stimulator and two Grass Model PSIU constant-current isolation units via a mercury slip spring mounted approximately $60 \mathrm{~cm}$ above the radial arm maze. A miniature stretch cord extended to the animal from the end of a light aluminum arm, which was, in turn, attached perpendicularly to the freely rotating shaft of the mercury slip ring. The arm-and-stretch-cord arrangement allowed the animal complete freedom of movement on the maze. However, as a precaution against performance effects potentially attributable to restriction of movement caused by the swivel assembly, stimulation leads were attached to the animals for both baseline and electrical brain stimulation trials. On test days, bilateral amygdala stimulation $(30 \mathrm{~Hz}, .1-\mathrm{msec}$ pulse duration, 10-sec pulse train) was delivered contingent upon the animal's finding the food on the baited arm. The effective level of stimulation for each animal was determined by starting at a low intensity $(50 \mu \mathrm{A})$ and increasing the level in $10-\mu \mathrm{A}$ steps until alteration of maze performance was observed. Disruptive levels for individual animals ranged from 60 to $80 \mu \mathrm{A}$.

After completion of the 20 trials, each animal received 10 more trials with 10-sec exposure to the reinforcer signifying the presence of 5 pieces of Capt'n Crunch cereal at the 23-h delay test. On half the trials, amygdala stimulation was applied for $10 \mathrm{sec} \mathrm{im-}$ mediately after the $10 \mathrm{sec}$ of food consumption; no stimulation was applied on the other half of the trials.

After completion of the $23-\mathrm{h}$ delay trials, each animal was 
tested 20 times at a 20 -min retention test delay with and without amygdala stimulation during the 10 -sec consumption of either the Froot Loop or Cocoa Puff.

\section{Histology}

Following completion of all experimentation, the implanted rats were anesthetized with $1 \mathrm{ml}$ sodium pentobarbital, injected with heparin, and perfused under 160 -mm mercury pressure pericardially with $10 \%$ Formalin in isotonic saline. Brains were excised, stored in the $10 \%$ Formalin solution for 10 days, frozen, cut at $50-\mu$ sections through the electrode tracts, and stained with cresyl violet. Electrode placements within the amygdala were confirmed by reference to the König and Klippel (1963) atlas.

\section{RESULTS}

Histologically verified electrode placements (ventral tip of each bipolar electrode) are schematically presented in Figure 1. The electrodes are located in the central and basomedial amygdala nuclear regions.

Retention of the correct arm as a function of the expectation of 1 or 5 pieces of Capt'n Crunch cereal in the presence or absence of amygdala stimulation is shown in Figure 2. It can be seen that there is a magnitude of reinforcement effect with few errors (better retention) for the expectation of five pieces of food (actually, only one of the four animals made any errors) and many errors (no retention) for the expectation of 1 piece of food. Amygdala stimulation applied during the 10-sec exposure to the Froot Loop or Cocoa Puff totally disrupted the magnitude of reinforcement effect. That is, the animals made as many errors (no retention) with the expectation of 1 as they did with the expectation of 5 pieces of food.

An analysis of variance (Kirk, 1968) with two within repeated measures (stimulation vs. no stimulation and expectation of 1 vs. 5 pieces of food) revealed that there was a significant magnitude of reinforcement effect $[F(1,9)=6.31, p<.05]$ and a significant interaction between brain stimulation and magnitude of reinforcement $[F(1,9)=7.76, p<.05]$. Further Newman-Keuls tests revealed that, compared with all the other conditions, significantly fewer errors were made only in the condition of no brain stimulation with expectation of 5 pieces of food $(\mathrm{p}<.05)$.

Recently, it has been suggested that, at least in a one-trial passive avoidance learning situation, amygdala stimulation either during or after a trial is effective in producing a retention deficit (Phillips \& Le Piane, 1981). Thus, the effect of pre- vs. poststudyphase stimulation was tested only for the expectation of 5 pieces of food in the presence or absence of amygdala stimulation. The results, shown in Table 1, indicate that stimulation is effective in disrupting retention only when applied during 10-sec food exposure. An analysis of variance with two within repeated measures (stimulation vs. no stimulation and during vs. after) revealed that there was a significant effect due to the presence of stimulation

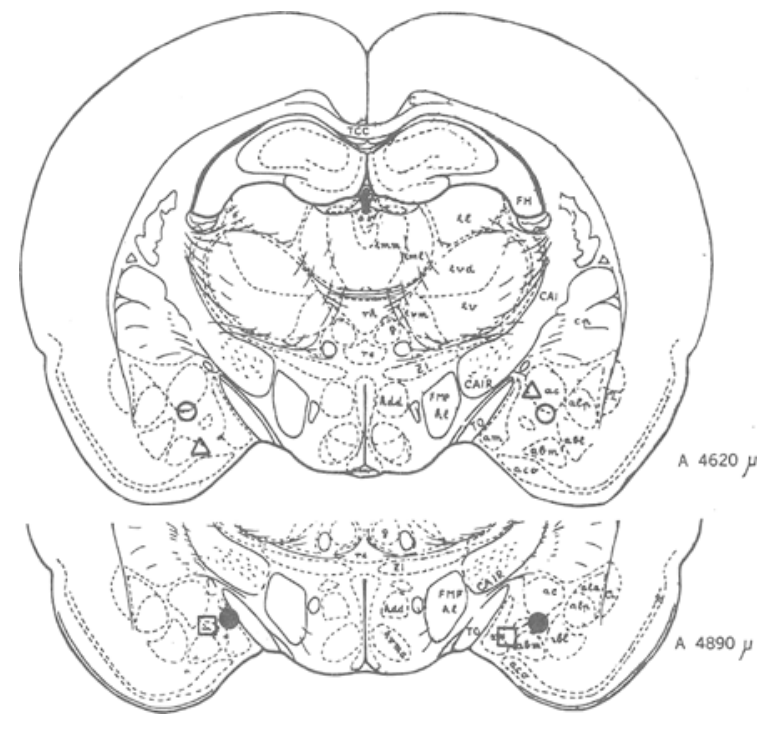

Figure 1. Bilateral electrode placements within the amygdala are shown for individual animals. Each animal is represented by a different symbol. Cross-sections were taken from the König and Klippel (1963) atlas.

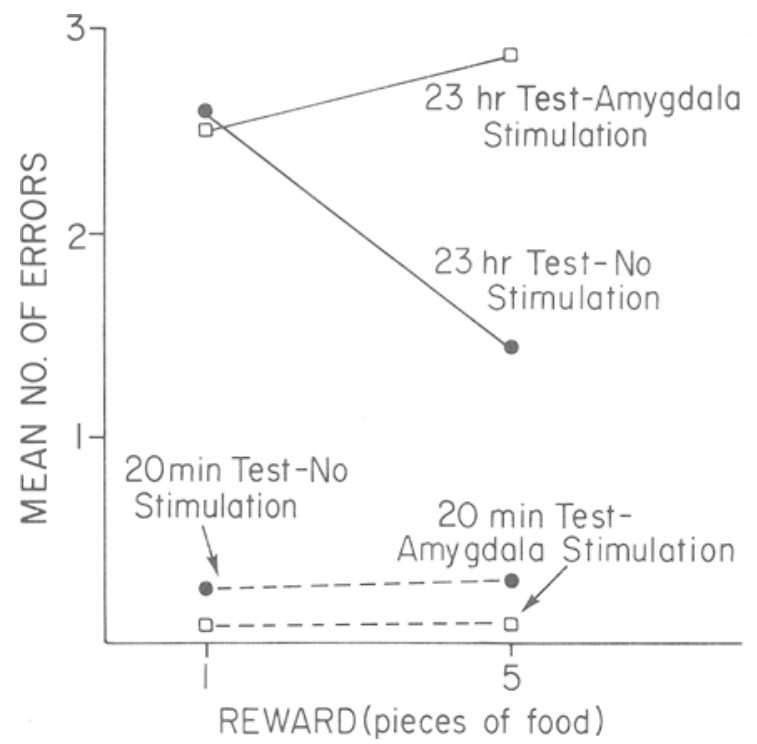

Figure 2. Mean number of errors per trial before entering the correct arm as a function of expectation of 1 or 5 pieces of food, time of retention test $(20 \mathrm{~min}$ or $23 \mathrm{~h}$ ), and presence or absence of amygdala stimulation.

$[F(1,9)=22.22, p<.01]$ and a significant interaction between brain stimulation and its application during or after 10 -sec exposure $[F(1,9)=8.64, p<.05]$. Further Newman-Keuls tests revealed that, compared with all the other conditions, significantly more errors were made only in the condition of brain stimulation during food exposure $(\mathrm{p}<.05)$.

The possibility exists, however, that amygdala stimulation was ineffective in producing more errors 
Table 1

Mean Number of Errors per Trial at the 23-h Retention Test Delay for the Expectation of Five Pieces of Food

\begin{tabular}{lcc}
\hline & $\begin{array}{c}\text { Amygdala } \\
\text { Stimulation }\end{array}$ & $\begin{array}{c}\text { No } \\
\text { Stimulation }\end{array}$ \\
\hline During & 3.00 & 1.05 \\
After & 1.95 & 1.50 \\
\hline
\end{tabular}

because there was a ceiling effect for the expectation of 1 piece of food. Thus, animals were tested at a 20-min retention test in the presence or absence of amygdala stimulation and with the expectation of 1 or 5 pieces of Capt'n Crunch cereal. The results, shown in Figure 2, indicate that (1) there is no magnitude of reinforcement effect (excellent retention for the expectation of both 1 or 5 pieces of food), and (2) amygdala stimulation had no disruptive effects for the expectation of either 1 or 5 pieces of food. An analysis of variance revealed that there were no significant effects. There were no seizures present at the level of stimulation used either before or after the testing period.

\section{DISCUSSION}

The data indicate that subseizure levels of amygdala stimulation during the 10 -sec exposure to the food cue resulted in a disruption of retention of the correct arm at a 23-h delay, given the expectation of a large food reward. As a matter of fact, performance at the 23-h retention test was at chance (i.e., the mean number of errors made during the retention test was similar to the number of arms visited during the study phase). This disruptive effect does not occur when similar amygdala stimulation is applied after the 10-sec exposure to the food cue or when retention tests were given at a 20 -min delay. The absence of a disruptive effect at the 20-min retention test delays rules out possible proactive interference effects on performance and possible statedependency effects.

Instead, these data suggest that the amygdala is involved only when conditions are such that one can detect a magnitude of reinforcement effect or when one employs a sufficiently large magnitude of reward for the appropriate retention test delay. Furthermore, the amygdala is not involved when low magnitudes of reward are used.

These data might then provide an explanation for the earlier failures to detect amygdala involvement in memory for specific experiences in appetitive situations (Berman \& Kesner, 1976; Goddard, 1964; Sanghera, Rolls, \& Roper-Hall, 1979). Presumably, in the above situations only weak positive affective attributes were activated, with perhaps little involvement of the amygdala. The present data are also consistent with Gold et al.'s (1975) findings that amyg- dala stimulation had a disruptive effect only when strong, but not weak, FSs were used. Thus, it appears that the amygdala is involved in mnemonic processing of information in situations using both positive and negative reinforcement contingencies, providing the input is of sufficient intensity to activate presumably emotional reactions.

It has been suggested that different effects of brain stimulation applied during or after the study phase (training experience or learning trial) reflect whether or not brain stimulation affects encoding or consolidation of critical information (Berman \& Kesner, 1981; Kesner \& Wilburn, 1974). It is assumed that EBS affects the encoding process when the treatment is effective only when applied during the study phase, the consolidation process when the treatment is effective only when applied after the study phase, and both encoding and consolidation processes when the treatment is effective when applied both during and after the study phase. In the case of the amygdala, it has been shown that, in one-trial passive avoidance learning situations, amygdala stimulation both during and after training results in a subsequent retention deficit (Baker, Kesner, \& Michal, 1981; Bresnahan \& Routtenberg, 1972; Phillips \& Le Piane, 1981). In the present study, amygdala stimulation applied during, but not after, the 10-sec exposure to the appropriate cue resulted in a long-term retention deficit for expectation of a large reward. Based on the above suggestion, it would then appear that amygdala stimulation interferes only with encoding, and not with consolidation, of critical attributes (emotional) of the memory trace. There is a serious problem with this interpretation. It is not necessarily true that a disruptive effect following stimulation during the study phase reflects an impairment of the encoding process. The possibility exists that, in familiar situations, both encoding and consolidation occur rather rapidly and, thus, that both could have been activated during the study phase. From a functional viewpoint, it might be somewhat arbitrary to emphasize too greatly the nominal distinction of during and after the study phase.

A more parsimonious explanation would be to suggest that amygdala stimulation is effective to the extent that the critical information to be processed involves critical neuronal changes within the amygdala, that is, when the amygdala is in an active state. Whenever the amygdala is in an inactive state, either because of cessation of critical neuronal activation or lack of activation due to the presence of a weak reinforcer, amygdala stimulation should be ineffective. Even though this explanation does not provide for criteria to separate encoding from consolidation, it does suggest that the amygdala is activated primarily in the presence of intense positive or negative reinforcers and that the duration of amygdala activation can vary between tasks (spatial delayed matching 
to sample and passive avoidance). One parameter that is known to decrease consolidation time is familiarity (Lewis, 1976). In the present experiment, in contrast to the one-trial passive avoidance experiments, there is a great deal of familiarity with the information to be processed, and, thus, it is perhaps not surprising that the amygdala needs to be activated for no more than $10 \mathrm{sec}$ during exposure to the correct arm and the food cue predicting a large reward. In conclusion, the data support Kesner's proposal that the amygdala mediates the encoding, consolidation, and perhaps retrieval of both positive and negative emotional attributes of a specific memory, providing the reinforcement input is of sufficient intensity to elicit a strong emotional reaction.

\section{REFERENCES}

Baker, L. J., Kesner, R. P., \& Michal, R. E. Differential effects of a reminder cue on amnesia induced by stimulation of amygdala and hippocampus. Journal of Comparative and Physiological Psychology, 1981, 95, 312-321.

Ben-Ari, Y., \& Le Gal La Salle, G. Plasticity at unitary level. II. Modifications during sensory association procedures. Electroencephalography and Clinical Neurophysiology, 1972, 32, 667-679.

Berman, R. F., \& Kesner, R. P. Posttrial hippocampal, amygdaloid, and lateral hypothalamic electrical stimulation: Effects on short- and long-term memory of an appetitive experience. Journal of Comparative and Physiological Psychology, 1976, 90, 260-267.

Berman, R. F., \& KeSNer, R. P. Electrical stimulation as a tool in memory research. In M. M. Patterson \& R. P. Kesner (Eds.), Electrical stimulation research techniques. New York: Academic Press, 1981.

Bresnahan, E., \& Routtenberg, A. Memory disruption by unilateral low level, subseizure stimulation of the medial amygdaloid nucleus. Physiology \& Behavior, 1972, 9, 513-525.

Goddard, G. V. Functions of the amygdala. Psychological Bulletin, 1964, 62, 89-109.

Gold, P. E., Hankins, L. L., Edwards, R., Chester, J., \& McGaugh, J. L. Memory interference and facilitation with posttrial amygdala stimulation: Effect on memory varies with footshock level. Brain Research, 1975, 86, 509-513.

Heath, R. Pleasure response of human subjects to direct stimulation of the brain: Physiologic and psychodynamic considerations. In R. Heath (Ed.), The role of pleasure in behavior. New York: Hoeber Medical Division, Harper \& Row, 1964.

Heath, R., \& Gallant, D. Activity of the human brain during emotional thought. In R. Heath (Ed.), The role of pleasure in behavior. New York: Hoeber Medical Division, Harper \& Row, 1964.

Huston, J. P., Mueller, C. C., \& Mondadori, C. Memory facilitation by posttrial hypothalamic stimulation and other reinforcers: A central theory of reinforcement. Biobehavioral Reviews, 1977, 1, 143-150.

Jones, B., \& Mishin, M. Limbic lesions and the problem of stimulus-reinforcement associations. Experimental Neurology, 1972, 36, 362-377.

KAADA, B. R. Stimulation and regional ablation of the amygdaloid complex with reference to functional representation. In B. E. Eleftheriou (Ed.), The neurobiology of the amygdala. New York: Plenum Press, 1972.
Kemble, E. D., \& Beckman, G. J. Runway performance of rats following amygdaloid lesions. Physiology \& Behavior, 1970, 5, 45-47.

KESNER, R. P. A neural system approach to the study of memory storage and retrieval. In R. R. Drucker-Colin \& J. L. McGaugh (Eds.), Neurobiology of sleep and memory. New York: Academic Press, 1977.

KESNER, R. P. The role of the amygdala within an attribute analysis of memory. In Y. Ben-Ari (Ed.), The amygdaloid complex revisited. Amsterdam: Elsevier, 1981.

KeSNer, R. P., \& Conner, H. S. Effects of electrical stimulation of rat limbic system and midbrain reticular formation upon short- and long-term memory. Physiology \& Behavior, 1974, 12, 5-12.

Kesner, R. P., \& Wilburn, M. W. A review of electrical stimulation of the brain in context of learning and retention. Behavioral Biology, 1974, 10, 259-293.

KIRK, R. E. Experimental design: Procedures for the behavioral sciences. Belmont, Calif: Brooks/Cole, 1968.

KöNIG, J. F. R., \& KLIPPEL, R. A. The rat brain: A stereotaxic atlas of the forebrain and lower parts of the brain stem. Baltimore, Md: Williams \& Wilkins, 1963.

LEWIS, D. J. A cognitive approach to experimental amnesia. American Journal of Psychology, 1976, 89, 51-80.

Lidsky, T. I., Levine, M. S., Kreinick, C. J., \& Schwartzbaum, J. S. Retrograde effects of amygdaloid stimulation on conditioned suppression (CER) in rats. Journal of Comparative and Physiological Psychology, 1970, 73, 135-149.

MARK, V. H., \& ERVIN, F. R. Violence and the brain. New York: Harper \& Row, 1970.

McDonough, J. H., Jr., \& Kesner, R. P. Amnesia produced by brief electrical stimulation of the amygdala or dorsal hippocampus in cats. Journal of Comparative and Physiological Psychology, 1971, 77, 171-178.

NARABAYASHI, M. Stereotaxic amygdalectomy. In B. F. Eleftheriou (Ed.), The neurobiology of the amygdala. New York: Plenum Press, 1972.

Norton, P. R. E. Differences in the electrophysiological correlates upon receipt of a food reward and non-reward in the rat. Brain Research, 1970, 24, 134-138.

Olton, D. S., \& Samuelson, R. J. Remembrance of places passed: Spatial memory in rats. Journal of Experimental Psychology: Animal Behavior Processes, 1976, 2, 97-116.

Phillips, A. G., \& LePiane, F. G. Differential effects of electrical stimulation of amygdala or caudate on inhibitory shock avoidance: A role for state-dependent learning. Behavioral Brain Research, 1981, 2, 103-111.

RICHARDSON, J. S. The amygdala: Historical and functional analysis. Acta Neurobiologiae Experimentalis, 1973, 33, 623-644.

Sanghera, M. K., Rolls, E. T., \& Roper-Hall, A. Visual responses of neurons in the dorsolateral amygdala of the alert monkey. Experimental Neurology, 1979, 63, 610-626.

Schwartzbaum, J. S. Changes in reinforcing properties of stimuli following ablation of the amygdaloid complex in monkeys. Journal of Comparative and Physiological Psychology, 1960, 53, 388-395.

WEISKRANTz, L. Behavioral changes with ablation of the amygdaloid complex in monkeys. Journal of Comparative and Physiological Psychology, 1956, 49, 381-391.

Wurtz, R. H., \& OLDs, J. Amygdaloid stimulation and operant reinforcement in the rat. Journal of Comparative and Physiological Psychology, 1963, 56, 941-949.

(Manuscript received December 18, 1981; accepted for publication February 10,1982.) 